\title{
Correction: Assessing the Use of Wrist-Worn Devices in Patients with Heart Failure: Feasibility Study
}

Yasbanoo Moayedi ${ }^{1}$, MD; Raghad Abdulmajeed ${ }^{2}$, MHSc; Juan Duero Posada ${ }^{1}$, MD; Farid Foroutan ${ }^{1}$, BSc; Ana Carolina Alba ${ }^{1}$, MD, PhD; Joseph Cafazzo ${ }^{2}$, PEng, PhD; Heather Joan Ross ${ }^{1}$, MD, MHSc

${ }^{1}$ Ted Rogers Centre of Excellence in Heart Function, University Health Network, Toronto, ON, Canada

${ }^{2}$ Centre for Global eHealth Innovation, Techna Institute, University Health Network, Toronto, ON, Canada

\section{Corresponding Author:}

Heather Joan Ross, MD, MHSc

Ted Rogers Centre of Excellence in Heart Function

University Health Network

Toronto General Hospital

190 Elizabeth $\mathrm{St}$

Toronto, ON, M5G 2C4

Canada

Phone: 14163403482

Email: heather.ross@uhn.ca

\section{Related Article:}

Correction of: http://cardio.jmir.org/2017/2/e8/

(JMIR Cardio 2018;2(1):e10149) doi: 10.2196/10149

The authors of the paper "Assessing the Use of Wrist-Worn Devices in Patients with Heart Failure: Feasibility Study" (Cardio JMIR 2017;1 (2): July-Dec) made a mistake by including a patient who had heart failure with preserved ejection fraction. This finding was just brought to the authors' attention. They apologize for this oversight but have taken all measures to ensure that correct data is displayed in the article.

In the Introduction section, the following has been removed from the end of the final sentence:

...with reduced ejection fraction (HFrEF; ejection fraction <40\%) anda NYHA Class II and III, as measured by daily steps by these two devices.

In the Methods section, the mention of "HFrEF" has been changed to "HF". "HFrEF" has also been removed from the paper's Abbreviations list.

In the Results section, the second and third sentences of the paragraph beginning with "Table $1 . .$. " has been changed to the following:

Patients were predominantly male (5/8, 63\%), with an average age of 58 years and ischemic cardiomyopathy $(5 / 8,63 \%)$. All patients were on guideline-directed medical therapy including a betablocker and either an angiotensin-converting enzyme (ACE) inhibitor or angiotensin-receptor blocker $(A R B)$ when indicated.
Specifically, the text which was previously " $(6 / 8,75 \%)$ " now reads " $(5 / 8,63 \%)$ ". The average age was " 57 " and is now " 58 ", and the phrase "when indicated" has been added to the end of the latter sentence.

The caption for Table 1 has been shortened from "Demographics and baseline data of patients included in phase 2 of the study" to "Demographics and baseline data". In Table 1 itself, data for Patient 7 has been changed under the following columns:
Age (years): "51" changed to " 58 "
Gender: "Male" changed to "Female"
LVEF", \%: "35" changed to "60"
Etiology of $\mathbf{H F}^{\mathbf{b}}$ : "Ischemic" changed to "Familial"
Medications d, Betablocker: "Carvedilol 12.5 mg" changed to "None"

Medications ${ }^{\mathrm{d}}$, Other: "Ramipril $10 \mathrm{mg}$ " changed to "None"

The updated version of Table 1 is available below.

The corrected article will appear in the online version of the paper on the JMIR website on May 4, 2018, together with the publication of this correction notice. Because this was made after submission to PubMed, Pubmed Central, and other full-text repositories, the corrected article also has been re-submitted to those repositories. 
Table 1. Demographics and baseline data.

\begin{tabular}{|c|c|c|c|c|c|c|c|c|}
\hline Number & Age (years) & Gender & LVEF $^{\mathrm{a}}, \%$ & Etiology of $\mathrm{HF}^{\mathrm{b}}$ & $\begin{array}{l}\text { NYHA }^{\mathrm{c}} \\
\text { class }\end{array}$ & $\begin{array}{l}\text { Medications }{ }^{\mathrm{d}} \\
\text { Betablocker }\end{array}$ & Amiodarone & Other \\
\hline 1 & 67 & Male & 40 & Ischemic & 3 & Bisoprolol $2.5 \mathrm{mg}$ & None & Candesartan $8 \mathrm{mg}$ \\
\hline 2 & 68 & Male & 18 & Ischemic & 2 & Bisoprolol $10 \mathrm{mg}$ & 200 & Irbesartan $300 \mathrm{mg}$ \\
\hline 3 & 63 & Male & 25 & Ischemic & 3 & Bisoprolol $10 \mathrm{mg}$ & None & Perindopril $8 \mathrm{mg}$ \\
\hline 4 & 61 & Female & 27 & Non-ischemic & 2 & Bisoprolol $10 \mathrm{mg}$ & None & Perindopril $4 \mathrm{mg}$ \\
\hline 5 & 52 & Male & 25 & Ischemic & 2 & Bisoprolol $10 \mathrm{mg}$ & None & Perindopril $8 \mathrm{mg}$ \\
\hline 6 & 57 & Female & 27 & Non-ischemic & 3 & Carvedilol $25 \mathrm{mg}$ & None & Ramipril $2.5 \mathrm{mg}$ \\
\hline 7 & 58 & Female & 60 & Familial & 2 & None & None & None \\
\hline 8 & 35 & Male & 33 & Hypertrophic & 3 & Carvedilol $50 \mathrm{mg}$ & None & Ramipril 10 mg \\
\hline
\end{tabular}

${ }^{a}$ LVEF: left ventricular ejection fraction.

${ }^{\mathrm{b}} \mathrm{HF}$ : heart failure.

${ }^{\mathrm{c}}$ NYHA: New York Heart Association.

${ }^{\mathrm{d}}$ Drug doses are total daily dose.

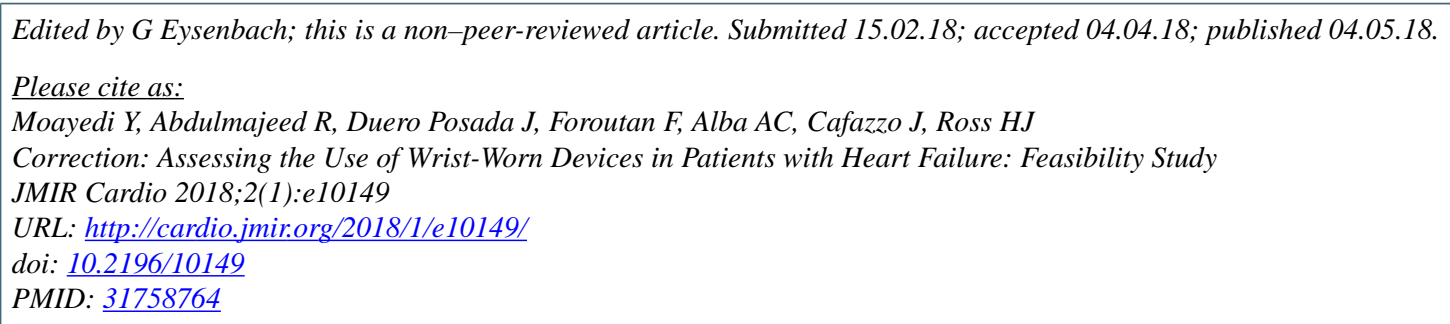

(C) Yasbanoo Moayedi, Raghad Abdulmajeed, Juan G. Duero Posada, Farid Foroutan, Ana Carolina Alba, Joseph A. Cafazzo, Heather J. Ross. Originally published in JMIR Cardio (http://cardio.jmir.org), 04.05.2018. This is an open-access article distributed under the terms of the Creative Commons Attribution License (https://creativecommons.org/licenses/by/4.0/), which permits unrestricted use, distribution, and reproduction in any medium, provided the original work, first published in JMIR Cardio, is properly cited. The complete bibliographic information, a link to the original publication on http://cardio.jmir.org, as well as this copyright and license information must be included. 